\title{
EVALUASI KETAHANAN GEMPA RUMAH SEDERHANA DI KELURAHAN RUM, KOTA TIDORE KEPULAUAN
}

\author{
Ahmad Aldo ${ }^{1}$ dan Galeh Nur Indriatno Putra Pratama ${ }^{1}$ \\ Jurusan Pendidikan Teknik Sipil dan Perencanaan, Fakultas Teknik, Universitas Negeri Yogyakarta \\ Email: ahmadaldo@gmail.com
}

\begin{abstract}
The aim of this study was to determine the level of resilience/ feasibility of simple houses on Rum Village against earhquakes. Simple house is restricted to building area of $\leq 70 \mathrm{~m}^{2}$. In this study, the simple houses that will be observe are grouped into four levels of feasibility consisting of: (1) very suitable; (2) quite suitable; (3) less suitable; and (4) unsuitable. The research was carried out on 28 July - 04 August 2019. The research was carried out through a survey of 35 simple houses in Rum Village, Tidore Kepulauan City, North Maluku Province. The sample of houses was chosen randomly and evenly based on the level of density of RT 1-RT 13, with the exception of RT 10. From the results, it was found that 6 houses (17\%) were categorized as very suitable for earthquake. Furthermore, 5 houses (12\%) were classified as suitable, 21 houses (60\%) were classified as less suitable, and 3 houses (8\%) were classified as unsuitable. After the interview with the foreman, the number of houses that are less suitable for earthquakes is caused by there is no reinforcement concrete beam sloof as a lower structure. Lack of budget is a major factor that make sloof is not build on the simple houses. Therefore, recommendations were made to the relevant government in the Tidore Kepulauan City to provide housing construction subsidies in the form of budget/ building materials. In addition, the government can innovate alternative building materials as a substitute for reinforcement concrete which is cheaper but still strong enough.
\end{abstract}

Keywords: earthquakres, houses, concrete

\begin{abstract}
ABSTRAK
Tujuan penelitian ini adalah untuk mengetahui tingkat ketahanan/ kelayakan rumah tipe sederhana di Kelurahan Rum terhadap gempa bumi. Rumah sederhana dibatasi untuk tempat inggal dengan luas bangunan $\leq 70 \mathrm{~m}^{2}$. Dalam penelitian ini, rumah sederhana yang akan ditinjau dikelompokkan menjadi empat tingkatan kelayakan yang terdiri atas: 1) sangat cocok; 2) cukup cocok; 3) kurang cocok; dan 4) tidak cocok. Kegiatan dilaksanakan pada tanggal 28 juli - 04 agustus 2019. Penelitian dilakukan melalui survey terhadap 35 rumah sederhana di Kelurahan Rum, Kota Tidore Kepulauan, Provinsi Maluku Utara. Sampel rumah dipilih secara acak dan merata berdasarkan tingkat kepadatan dari RT 1 -RT 13, terkecuali RT 10. Dari hasil analisis survey, diketahui bahwa 6 rumah (17\%) masuk kategori sangat cocok ketahanannya terhadap gempa bumi. Selanjutnya, 5 rumah $(12 \%)$ tergolong cukup cocok, 21 rumah $(60 \%)$ tergolong kurang cocok, dan 3 rumah (8\%) tergolong tidak cocok. Setelah dilakukan wawancara dengan mandor setempat, banyaknya rumah yang kurang cocok terhadap gempa bumi disebabkan oleh tidak terbangunnya beton sloof sebagai struktur bangunan bagian bawah. Kurangnya anggaran menjadi faktor penyebab utama tidak terbangunnya sloof bagi rumah tinggal sederhana. Oleh karena itu, disusun rekomendasi kepada pemerintah terkait di Kota Tidore Kepulauan untuk memberkan subsidi pembangunan rumah berupa anggaran/ bahan bangunan. Selain itu, pemerintah dapat melakukan inovasi bahan bangunan alternatif sebagai pengganti beton bertulang yang lebih murah namun cukup kuat.
\end{abstract}

Kata kunci: gempa bumi, rumah, beton 


\section{PENDAHULUAN}

Sejarah gempa bumi sudah ada selama manusia hidup dan merupakan salah satu sumber bencana alam yang berbahaya terhadap aktivitas manusia. Berdasarkan faktor penyebabnya, gempa bumi merupakan fenomena alam yang dapat terjadi akibat pergeseran lempeng, aktivitas vulkanis gunung aktif, dan hantaman keras benda dari luar bumi. Namun, selama ini pergeseran lempeng menjadi faktor utama penyebab terjadinya gempa bumi di dunia, khususnya di Indonesia.

Pergeseran lempeng merupakan aktivitas yang belum dapat diprediksi oleh manusia.
Pergeseran yang besar dapat mengakibatkan kerusakan yang cukup fatal, seperti kerusakan rumah tinggal dan bangunan infrastruktur masyarakat. Oleh karena itu, gempa bumi dengan kekuatan besar menjadi sumber bencana yang wajib diwaspadai dan disiapkan oleh manusia. Salah satu daerah yang sering terjadi gempa bumi adalah Provinsi Maluku Utara. Provinsi yang terletak di wilayah timur Indonesia ini menjadi titik persinggungan tiga lempeng besar yang melintasi wilayah Indonesia. Sebaran titik dan jumlah kejadian gempa bumi di Provinsi Maluku Utara dapat dilihat pada Gambar 1 berikut.

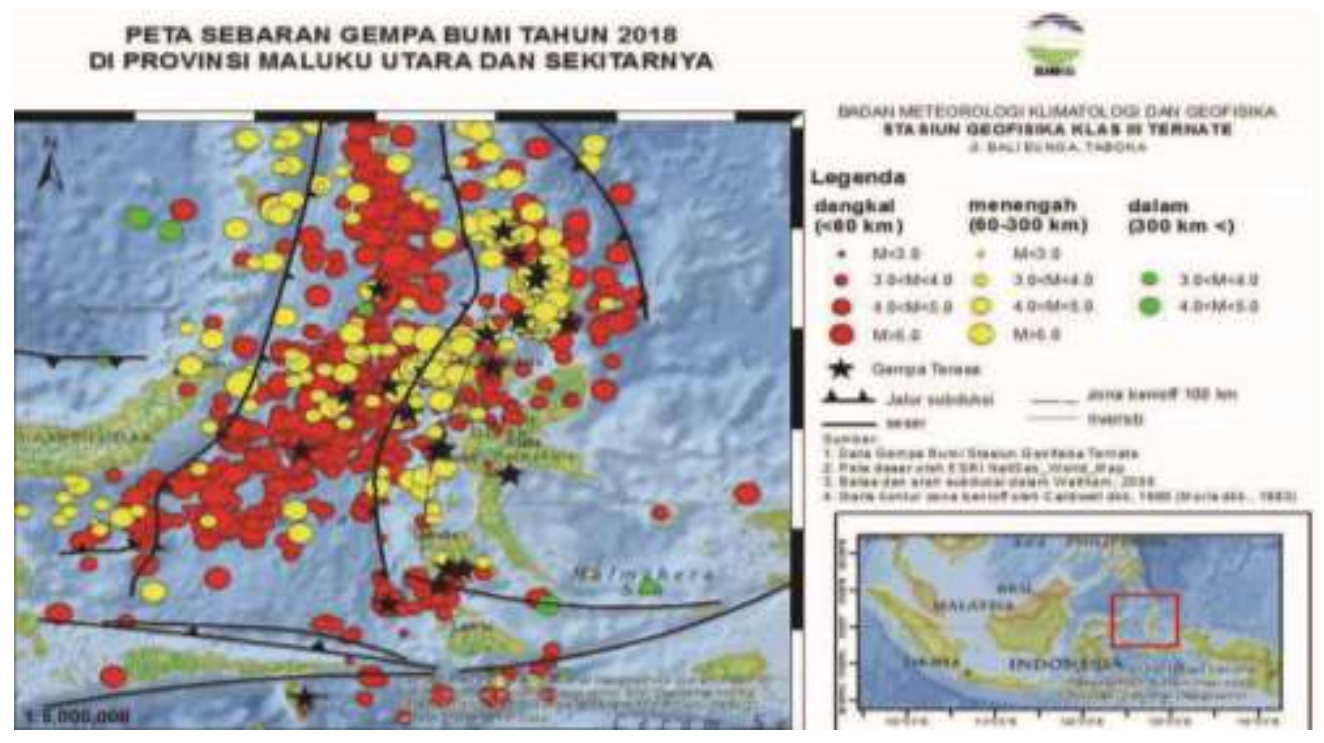

Gambar 1. Peta Sebaran Gempa Bumi Provinsi Maluku Utara

(Sumber: Badan Meteorologi Klimatologi dan Geofisika (BMKG), 2018)

Berdasarkan banyaknya kejadian gempa di Maluku Utara, perlu digarisbawahi bahwa fenomena gempa bumi bukanlah bencana yang secara langsung menimbulkan korban jiwa. Namun, bangunan yang runtuh adalah penyebab utama timbulnya korban dari gempa bumi. Untuk merekayasa bangunan tahan gempa, pihak Pemerintah melalui Kementerian Pekerjaan Umum telah merilis Pedoman Teknis Rumah Tinggal Sederhana Tahan Gempa tahun 2006. Pedoman ini diharapkan dapat diterapkan pada zona rawan gempa bumi seperti di Maluku Utara.
Ciri-ciri dari rumah tinggal yang tahan terhadap gempa adalah bangunan yang ringan dan bersifat daktail. Bangunan ringan akan memperkecil efek gempa yang dirasakan oleh bangunan. Sementara itu, daktail merupakan sifat ketahanan bangunan untuk berdiri kokoh dalam beberapa saat sebelum runtuh. Sifat ini perlu terpenuhi agar ketika terjadi gempa, manusia yang beraktivitas di dalamnya memiliki kesempatan untuk dapat menyelamatkan diri terlebih dahulu dengan keluar dari bangunan tersebut. Berdasarkan Pedoman Teknis Bangunan Tahan Gempa (2006) bangunan bersifat daktail yang tahan terhadap bencana

INERSIA, Vol. XV No. 2, November 2019 
gempa bumi adalah bangunan yang memiliki bagian struktural lengkap, meliputi pondasi, sloof, kolom, balok latei, dan ring balok.

Salah satu daerah yang masuk kategori rawan gempa di Provinsi Maluku Utara adalah Kelurahan Rum, Kota Tidore Kepulauan. Kelurahan ini terletak di pulau Tidore dan langsung menghadap ke laut. Setelah dilakukan observasi bangunan rumah tinggal sederhana di kelurahan Rum, diketahui secara visual bahwa ada beberapa rumah tinggal yang belum memenuhi sifat daktail untuk menjadi rumah tahan gempa. Sebagian rumah tinggal tersebut tidak memiliki komponen struktural daktail yang lengkap, kekurangan tersebut dapat beranekaragam seperti tidak terdapatnya sloof/ balok latei/ ring balok.

Fakta tersebut tentu harus dibuktikan secara valid, karena apabila rumah tinggal sederhana bagi masyarakat di kelurahan Rum tidak tahan terhadap gempa bumi,

\section{METODE}

\section{Jenis Penelitian}

Penelitian ini dilaksanakan dengan menggunakan jenis penelitian kuantitatif. Jenis kuantitatif dipilih karena penelitian ini dilakukan untuk mengetahui persentase kelayakan rumah tinggal sederhana di kelurahan Rum terhadap ketahanan gempa. Kriteria kelayakan tersebut dibedakan menjadi empat kategori, yaitu 1) Sangat cocok; 2) Cukup cocok; 3) Kurang cocok; dan 4) Tidak cocok.

\section{Tempat dan Waktu Penelitian}

Tempat penelitian dilaksanakan di pemukiman penduduk yang masuk dalam bagian wilayah Kelurahan Rum. Sedangkan waktu penelitian diadakan pada tanggal 28 juli - 04 agustus 2019.

\section{Subjek Penelitian}

Subjek pada penelitian ini adalah rumah masyarakat di kelurahan Rum dengan dikhawatirkan gempa bumi besar dapat meruntuhkan bangunan masyarakat. Sebagai langkah tindak lanjut dari kekhawatiran tersebut, dilakukan penelitian untuk mengevaluasi kesesuaian rumah tinggal sederhana di kelurahan Rum terhadap standar bangunan tahan gempa. Oleh karena itu, penelitian ini dilakukan dengan judul "Evaluasi Kesesuaian Rumah Tinggal Sederhana Terhadap Standar Rumah Tahan Gempa" dengan studi kasus di Kelurahan Rum, Kota Tidore Kepulauan.

Adapun luaran dari penelitian ini diharapkan dapat menjadi rekomendasi bagi pemerintah daerah, yang dalam hal ini Dinas Pekerjaan Umum Kota Tidore Kepulauan untuk menerapkan berinovasi agar rumah tinggal yang didirikan ke depan dapat memenuhi syarat tahan gempa. Selain itu, diharapkan dari penelitian ini dapat dipublikasikan dalam jurnal ilmiah agar dapat menjadi acuan sumber bacaan bagi pihak yang hendak melakukan evaluasi serupa di daerah lainnya.

kriteria jenis rumah tinggal sederhana. Acuan rumah tinggal sederhana didasari atas teori yang tercantum dalam Pedoman Teknis Bangunan Tahan Gempa (2006). Dalam keputusan tersebut rumah tinggal sederhana adalah bangunan dengan luas lantai bangunan $\leq 70 \mathrm{~m} 2$ dan luas tanah $\leq$ $200 \mathrm{~m} 2$.

\section{Teknik dan Instrumen Pengumpulan Data}

1. Teknik Pengumpulan Data

Pengumpulan data dilakukan dengan beberapa teknik yang dibedakan berdasarkan data primer dan data sekunder. Data primer adalah jenis data yang dikumpulkan berdasarkan angket dan digunakan sebagai dasar analisis data. Sementara itu, data sekunder merupakan jenis data yang diperoleh peneliti berdasarkan wawancara dan dokumentasi terkait bentuk struktur rumah tinggal sederhana di kelurahan Rum, Kota Tidore Kepulauan. 
Angket digunakan untuk mendapatkan data spesifikasi rumah secara umum sehingga dapat dilakukan pada masyarakat yang awam mengenai bangunan. Sementara itu, wawancara dilakukan pada salah seorang warga yang menjadi kepala tukang/ mandor pada setiap pembangunan rumah sederhana di kelurahan Rum. Oleh karena itu, hasil wawancara tentu dapat merepresentasikan spesifikasi rinci tentang bangunan rumah tinggal masyarakat kelurahan Rum, khususnya pada bagian struktural.

Langkah pengumpulan data diawali dengan menyusun kriteria rumah sangat cocok terhadap ketahanannya dengan gempa, kemudian dilanjutkan berturut-turut menjadi cukup cocok, kurang cocok, dan tidak cocok. Kemudian dipilih referensi angket yang telah divalidasi dan disesuaikan terhadap kebutuhan penelitian di kelurahan Rum. Untuk itu, penelitian ini menggunakan angket dari Skripsi Adi (2016) dengan judul Evaluasi Kesesuaian Bangunan Rumah Tinggal Terhadap Aturan Rumah Sederhana Tahan Gempa di Kabupaten Purworejo. Referensi tersebut dipilih karena kesesuaian tujuan, manfaat, dan luaran dari penelitian yang diharapkan. Akan tetapi, dalam penelitian ini terdapat keterbaruan dari penelitian sebelumnya, yaitu tingkat kerawanan gempa. Untuk lebih jelasnya perhatikan Gambar 2 di bawah.

Berdasarkan gambar dapat dilihat wilayah Kecamatan Butuh, Kabupaten Purworejo berada di wilayah gempa tingkat 3, sedangkan kelurahan Rum, kota Tidore Kepulauan berada di wilayah tingkat 4 . Ini mengakibatkan ada potensi terjadinya gempa bumi yang lebih besar.

\section{Instrumen Pengumpulan Data}

Dalam penelitian ini, dipilih Instrumen pengumpulan data dengan angket dan wawancara. Pemilihan angket dan wawancara didasari atas kesesuaian untuk diterapkan pada jenis penelitian kuantitatif dan kemudahan dalam pengumpulan data di lapangan. Tujuan akhir angket adalah mengetahui persentase bagian struktural rumah di Kelurahan Rum yang sudah terpenuhi dan belum terpenuhi. Sementara wawancara bertujuan mengetahui secara rinci spesifikasi struktutal bangunan yang digunakan. Adapun instrumen angket dan wawancara disusun berdasarkan Pedoman Teknis Rumah dan Bangunan Gedung Tahan Gempa yang telah di rilis pada tahun 2006 lalu.

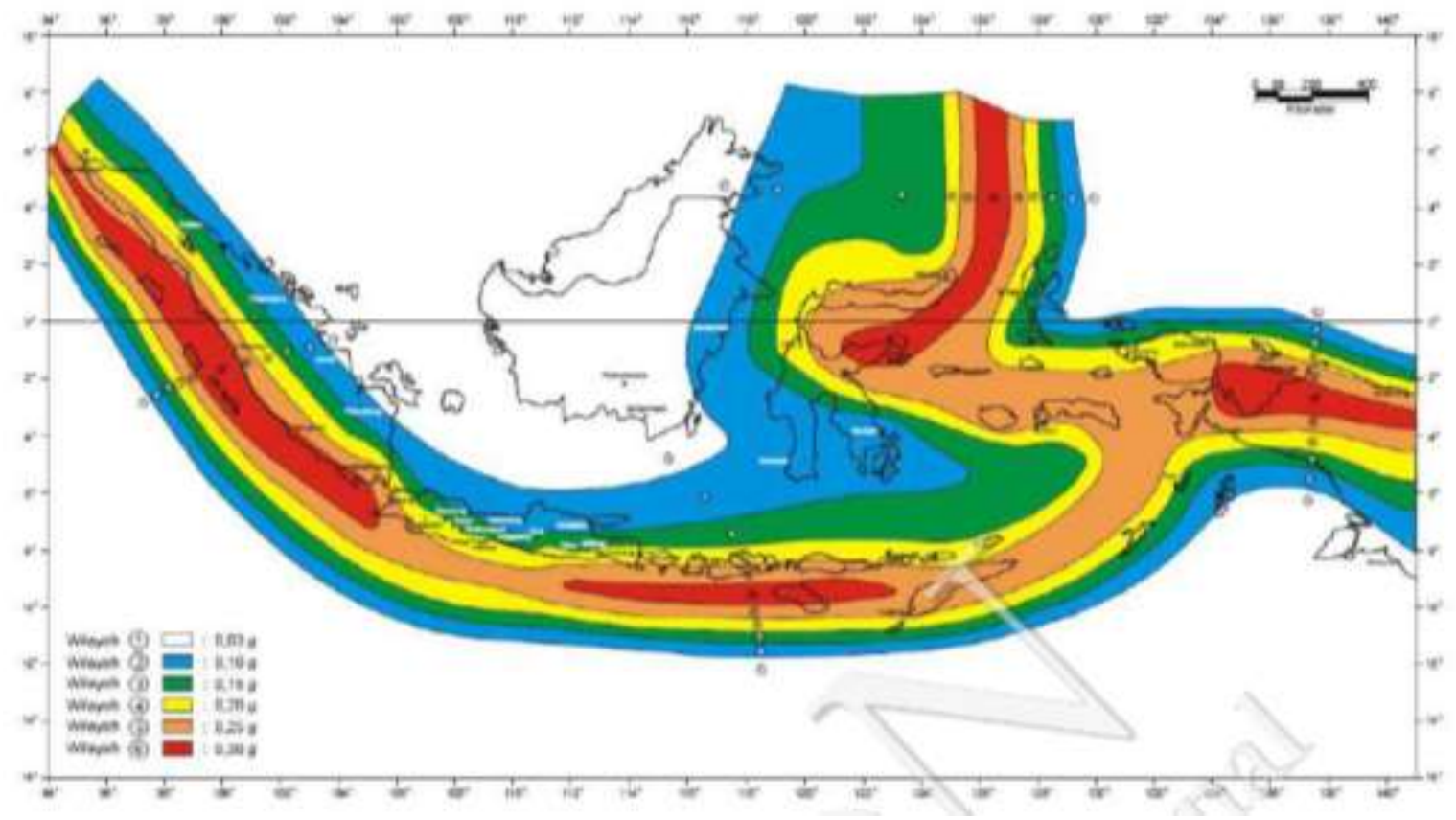

Gambar 2. Peta Zonasi Tingkat Kekuatan Gempa Berdasarkan Wilayah (Sumber: Buku Peta Sumber dan Bahaya Gempa Indonesia, 2017) 
Evaluasi Ketahanan ... (Ahmad/ hal 1-9)

Tabel 1. Kisi-kisi Instrumen Angket

\begin{tabular}{clc}
\hline Nomor & \multicolumn{1}{c}{ Pertanyaan } & Nomor Butir \\
\hline 1. & Apakah bangunan didirikan setelah tahun 2007? & 01 \\
2. & Apakah bangunan menggunakan pondasi batu kali ? & 02 \\
3. & Apakah bangunan menggunakan balok Sloof? & 03 \\
4. & Apakah bangunan menggunakan kolom? & 04 \\
5. & Apakah bangunan menggunakan balok lintel? & 05 \\
6. & Apakah bangunan menggunakan ring balok? & 06 \\
7. & Apakah bangunan menggunakan kuda-kuda yang menyatu dengan beton? & 07 \\
\hline
\end{tabular}

Tabel 2. Kisi-kisi Instrumen Wawancara

\begin{tabular}{|c|c|c|}
\hline Nomor & Pertanyaan & Nomor Butir \\
\hline 1. & $\begin{array}{l}\text { Apakah pondasi bangunan memiliki spesifikasi yang sesuai terhadap kriteria } \\
\text { berikut ini? } \\
\text { a. Tinggi pondasi } \geq 60 \mathrm{~cm} \\
\text { b. Lebar atas pondasi } \geq 20 \mathrm{~cm} \\
\text { c. Lebar bawah pondasi } \geq 70 \mathrm{~cm}\end{array}$ & 01 \\
\hline 2. & $\begin{array}{l}\text { Apakah sloof bangunan memiliki spesifikasi yang sesuai terhadap kriteria } \\
\text { berikut ini? } \\
\text { a. Diameter tulangan pokok } \geq 12 \mathrm{~mm} \\
\text { b. Diameter tulangan sengkang } \geq 8 \mathrm{~mm} \\
\text { c. Jarak as ke as sengkang } \geq 15 \mathrm{~cm}\end{array}$ & 02 \\
\hline 3. & $\begin{array}{l}\text { Apakah kolom bangunan memiliki spesifikasi yang sesuai terhadap kriteria } \\
\text { berikut ini? } \\
\text { a. Diameter tulangan pokok } \geq 10 \mathrm{~mm} \\
\text { b. Diameter tulangan sengkang } \geq 6 \mathrm{~mm} \\
\text { c. Jarak as ke as sengkang } \geq 15 \mathrm{~cm}\end{array}$ & 03 \\
\hline 4. & $\begin{array}{l}\text { Apakah balok lintel dari bangunan memiliki spesifikasi yang sesuai terhadap } \\
\text { kriteria berikut ini? } \\
\text { a. Diameter tulangan pokok } \geq 10 \mathrm{~mm} \\
\text { b. Diameter tulangan sengkang } \geq 6 \mathrm{~mm} \\
\text { c. Jarak as ke as sengkang } \geq 15 \mathrm{~cm}\end{array}$ & 04 \\
\hline 5. & $\begin{array}{l}\text { Apakah ring balok dari bangunan memiliki spesifikasi yang sesuai terhadap } \\
\text { kriteria berikut ini? } \\
\text { a. Diameter tulangan pokok } \geq 10 \mathrm{~mm} \\
\text { b. Diameter tulangan sengkang } \geq 6 \mathrm{~mm} \\
\text { c. Jarak as ke as sengkang } \geq 15 \mathrm{~cm}\end{array}$ & 05 \\
\hline 6. & $\begin{array}{l}\text { Apakah kuda-kuda dari bangunan memiliki spesifikasi yang sesuai terhadap } \\
\text { kriteria berikut ini? } \\
\text { a. Kuda-kuda diikat dengan balok dan kolom menggunakan besi tulangan } \\
\text { b. Setiap sambungan kayu dibuat menjadi kaku dengan paku }\end{array}$ & 06 \\
\hline
\end{tabular}

\section{Teknik Analisis Data}

Dalam proses analisis data, digunakan tipe analisis deskriptif. Oleh karena itu, hasil angket yang telah diisi oleh responden dijabarkan dalam bentuk tabel. Kemudian dari tabel tersebut dijabarkan penyebab dan langkah-langkah mengatasi permasalahan tersebut. Setelah itu, di akhir penjabaran akan dibahas solusi

konkrit untuk menyelesaikan
permasalahan yang ditemukan
berdasarkan fakta di lapangan. Solusi
tersebut akan diajukan kepada pemerintah
setempat sebagai rekomendasi
pembangunan rumah tinggal di masa yang
akan datang.




\section{HASIL DAN PEMBAHASAN}

\section{Profil Kelurahan Rum}

Kelurahan Rum terletak di pulau Tidore, menjadi bagian dari kecamatan Tidore Utara dan termasuk dalam pemerintahan Kota Tidore Kepulauan. Luas wilayah kelurahan Rum adalah $11.87 \mathrm{~km} 2$. Berdasarkan data tahun 2019, kelurahan Rum memiliki jumlah penduduk sebanyak 3347 jiwa. Artinya,

kepadatan penduduk di kelurahan Rum hanya 282 jiwa/km2. Selain itu, kelurahan Rum terdiri dari $13 \mathrm{RT}$ yang tergabung dalam $4 \mathrm{RW}$. Adapun pemetaan wilayah RT di kelurahan Rum dapat dilihat pada gambar berikut.

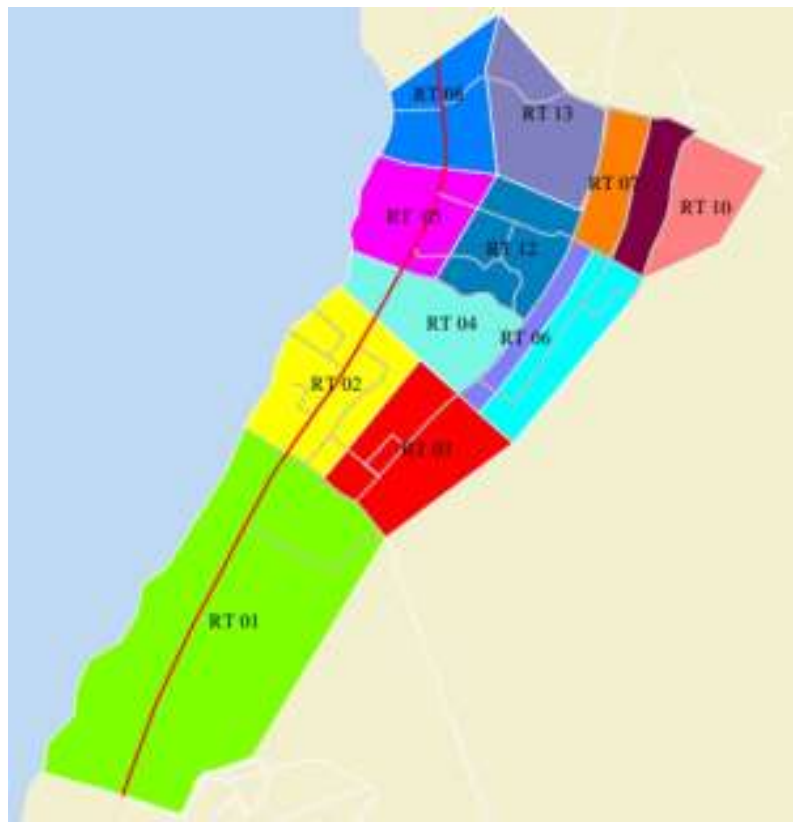

Gambar 3. Peta Kelurahan Rum Berdasarkan Jumlah RT (Sumber: Dokumen Pribadi, 2019)

Berdasarkan letak geografisnya, Kelurahan Rum menghadap ke pulau Maitara dan pulau Ternate di bagian utara. Secara lebih rinci, Rum terletak di pesisir laut pulau Tidore pada bagian utara. Oleh karena itu, potensi gempa yang terjadi di wilayah laut utara pulau Tidore dapat berdampak pada kerusakan bangunan kecamatan Tidore Utara, khususnya kelurahan Rum.
Jumlah sampel yang diambil ditentukan berdasarkan luasan wilayah setiap RT. Selain itu, RT 10 tidak diambil sampel karena terletak sangat jauh terhadap RT lainnya yang berdekatan. Maka, dihasilkan jumlah sampel rumah yang ditinjau berdasarkan RT masing-masing seperti pada bagian dari Tabel 3

Tabel 3. Jumlah Sampel pada Setiap RT

\begin{tabular}{cccc}
\hline Nomor RT & Sampel & Nomor RT & Sampel \\
\hline 1 & 6 & 7 & 2 \\
2 & 4 & 8 & 2 \\
3 & 4 & 9 & 2 \\
4 & 3 & 11 & 2 \\
5 & 3 & 12 & 3 \\
6 & 2 & 13 & 2 \\
\hline
\end{tabular}




\section{Data Hasil Penelitian}

Berdasarkan penelitian yang telah dilakukan, dari rumah tinggal sederhana di Kelurahan Rum terkumpul data yang variatif sesuai dengan pertanyaan dalam

angket. Berikut tabel persentase tanggapan responden selaku pemilik rumah terhadap angket yang telah diberikan.

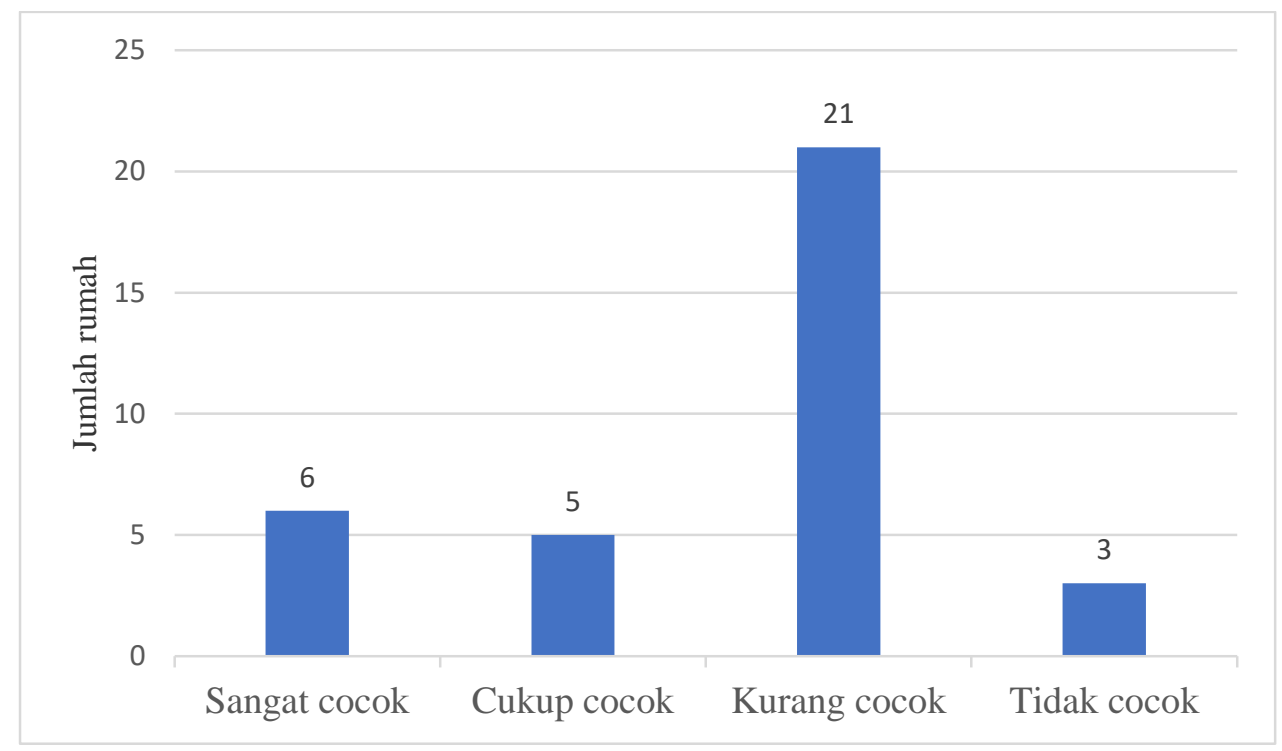

Gambar 4. Persentase Kualitas Rumah di Kelurahan Tum Terhadap Gempa Bumi

Tabel 4. Jumlah Sampel pada Setiap RT

\begin{tabular}{ccccc}
\hline \multirow{2}{*}{ Nomor Soal } & \multicolumn{3}{c}{ Terpenuhi } & Tanggapan Responden \\
Persentase & Jumlah & $\begin{array}{c}\text { Tidak terpenuhi } \\
\text { Persentase }\end{array}$ \\
\hline 1. & 35 & $100 \%$ & - & $0 \%$ \\
2. & 35 & $100 \%$ & - & $0 \%$ \\
3. & 11 & $31 \%$ & 24 & $69 \%$ \\
4. & 32 & $91 \%$ & 3 & $9 \%$ \\
5. & 6 & $17 \%$ & 29 & $83 \%$ \\
6. & 32 & $91 \%$ & 3 & $9 \%$ \\
7. & 35 & $100 \%$ & - & $0 \%$ \\
\hline
\end{tabular}

\section{Pembahasan Hasil Penelitian}

Berdasarkan data yang diperoleh, diketahui bahwa terdapat 21 rumah tinggal (60\%) dikategorikan kurang cocok dan 3 rumah tinggal $(8 \%)$ tidak cocok terhadap gempa bumi. Ini disebabkan karena 21 rumah tersebut tidak menggunakan balok sloof. Bahkan, 3 rumah lainnya juga tidak menggunakan kolom dan ring balok. Berdasarkan hasil wawancara dengan kepala tukang di kelurahan Rum, diketahui bahwa pembangunan rumah disesuaikan dengan kondisi keuangan masyarakat. Oleh karena itu, bagi masyarakat yang tidak memiliki keuangan mencukupi tetap akan dibangun suatu rumah namun tidak menggunakan struktur balok sloof. Bahkan, dari hasil wawancara terhadap pemilik 3 rumah yang tidak cocok diketahui bahwa rumah tersebut dibangun secara gotong royong antara pemilik rumah dan dibantu tetangga sekitar. Hal tersebut dilakukan karena dapat menghemat biaya pembangunan rumah tinggal. Berdasarkan dua fakta tersebut dapat diketahui bahwa faktor keuangan menjadi permasalahan masyarakat di kelurahan Rum dalam mewujudkan rumah tinggal yang tahan terhadap gempa bumi. 
Untuk kedepan, pandangan tentang pengurangan beton bagian sloof dalam menghemat biaya pembangunan harus segera dihentikan. Sebabnya, menjadikan bangunan kurang cocok menahan gempa bumi. Berdasarkan perhitungan anggaran, diketahui pembangunan beton sloof membutuhkan dana Rp 4.327.589,61/ m3. Untuk meninjau biaya yang lebih rinci, dilakukan perbandingan Rencana Anggaran Biaya (RAB) antara rumah tinggal sederhana yang menggunakan balok sloof dan tidak menggunakan balok sloof. Untuk desain denah disusun berdasarkan bentuk rumah yang paling sering digunakan masyarakat di Kelurahan Rum.

Untuk gambar di atas, RAB bagi denah yang menggunakan balok sloof membutuhkan dana $\mathrm{Rp}$ 186,086,397.66. Sementara rumah yang tidak menggunakan sloof membutuhkan anggaran sebesar Rp 176,782,080.00. Berdasarkan hasil perhitungan tersebut diketahui bahwa pembangunan sloof untuk bentuk denah di atas membutuhkan anggaran $\mathrm{Rp}$ $9,304,317.66$.

\section{Rekomendasi}

Berdasarkan pembahasan masalah di atas, disusun beberapa solusi yang dapat

\section{SIMPULAN}

Berdasarkan hasil analisis yang dilakukan, didapatkan beberapa kesimpulan sebagai berikut. (1) Enam rumah (17\%) masuk kategori sangat cocok ketahanannya terhadap gempa bumi. (2) Lima rumah (12\%) masuk kategori cukup cocok ketahanannya terhadap gempa bumi. (3) 21 rumah (60\%) masuk kategori kurang cocok terhadap gempa bumi. (4) Tiga rumah (8\%) tergolong

\section{DAFTAR RUJUKAN}

$\begin{array}{ccr}\text { Pusat Studi Gempa Nasional. 2017. Peta } \\ \text { Sumber dan Bahaya } & \text { Gempa } \\ \text { Indonesia } & \text { Tahun 2017. } & \text { Jakarta: } \\ \text { Badan } & \text { Penelitian } & \text { dan }\end{array}$

diterapkan dalam mengatasi permasalahan kurangnya biaya untuk pembangunan sloof sebagai bagian struktur bangunan seperti berikut.

1. Subsidi pembangunan rumah

a. Subsidi anggaran

Pemerintah Dinas Pekerjaan Umum Kota Tidore Kepulauan dapat memberikan subsidi dalam bentuk anggaran biaya pokok kepada masyarakat yang hendak membangun rumah tinggal dalam kategori sederhana. Besarnya biaya pokok dapat disesuaikan dengan kebutuhan anggaran pembangunan bagian balok sloof.

b. Subsidi bahan bangunan

Dari tabel 5 dapat diketahui bahwa $34 \%$ biaya pembuatan sloof berasal dari kebutuhan besi tulangan. Oleh karena itu, Pemerintah terkait dapat memberikan subsidi dalam bentuk bahan bangunan berupa besi sebagai material utama pembangunan struktur sloof.

\section{Inovasi bahan bangunan}

Dikarenakan harga tulangan semakin mahal, perlu dilakukan upaya mengenai langkah pengembangan bahan bangunan alternatif sebagai inovasi pengganti besi tulangan dalam konstruksi beton bertulang.

tidak cocok terhadap gempa bumi. Banyaknya rumah yang kurang cocok disebabkan tidak terbangunnya sloof sebagai struktur beton bagian bawah. Kurangnya anggaran masyarakat menjadi faktor utama penyebab tidak terbangunnya sloof pada rumah tinggal sederhana di Kelurahan Rum.

Pengembangan, Kementerian PUPR.

Ramadhan, M. A., Pratama, G. N. I. P., \& Hidayah, R. (2018). Penataan Sistem

INERSIA, Vol. XV No. 2, November 2019 
Evaluasi Ketahanan ... (Ahmad/ hal 1-9)

Jalur Pejalan Kaki di Universitas

aturan rumah sederhana tahan Negeri Yogyakarta. INformasi dan Ekspose hasil Riset Teknik Slpil dan Arsitektur, 14(1), 101-117.

gempa. Purworejo: Skripsi mahasiswa Universitas

Muhammadiyah Purworejo

Sunarjo, dkk. 2012. Gempa bumi edisi populer. Yogyakarta: BMKG

Sungging. 2015. Evaluasi kesesuaian bangunan rumah tinggal terhadap

Wijanarko, Agoes. 2006. Pedoman teknis bangunan tahan gempa. Jakarta: Direktorat Jenderal Cipta Karya, Kementerian Pekerjaan Umum (PU). 